\title{
METODOLOGIA PARA A POLINIZAÇÃO CONTROLADA EM Ilex paraguariensis A. St. Hil. - Aquifoliaceae ${ }^{1}$
}

Valderês Aparecida de Sousa ${ }^{2}$, Ananda Virgínia de Aguiar² e Janaína Spoladore ${ }^{3}$

\begin{abstract}
RESUMO - A erva-mate (Ilex paraguariensis A. St. Hil.) é uma espécie nativa brasileira de grande interesse econômico. Programas de melhoramento genético dessa espécie têm visado ao aumento da produtividade de biomassa e qualidade. A polinização controlada permite a combinação de características desejáveis da espécie. Para isso, técnicas adequadas de polinização controlada devem ser disponibilizadas. Este trabalho teve por objetivo definir uma metodologia para a polinização controlada de erva-mate. Para isso, utilizou-se um teste clonal de 15 anos de idade na Embrapa Florestas-Colombo-PR com nove tratamentos em flores de três árvores (repetições). As flores foram polinizadas em novembro de 2010 e os frutos, coletados em março de 2011. Os frutos e sementes produzidos foram quantificados e a viabilidade dos embriões, avaliada pelo teste de tetrazólio. Os dados foram analisados com base no procedimento GLM do programa R. Maior quantidade de frutos e sementes foi observada na polinização controlada comparativamente à polinização livre. Conclui-se que a polinização controlada após a antese dessa espécie deve ser realizada em dois dias consecutivos, para assegurar boa produção de sementes em erva-mate.
\end{abstract}

Palavras-chave: Erva-mate; Fenologia; Sementes.

\section{METHODOLOGY FOR THE CONTROLLED POLLINATION OF Ilex paraguariensis A. St. Hil. - Aquifoliaceae}

\begin{abstract}
Mate (Ilex paraguariensis A. S. Hil.) is an economically important Brazilian native species. Mate genetic improvement programs have been established basically aiming biomass productivity and product quality. Controlled pollination allows to combine desirable characteristics for this species. Thus, adequate controlled pollination techniques must be made available. This work aimed to develop a methodology for controlled pollination in mate. For that purpose, a 15 years old clonal test was used at Embrapa Florestas-Colombo-PR with nine treatments applied on three flowering trees (replications). Flowers were pollinated in November 2010 and the fruits were collected in March 2011. Fruits and seeds produced were quantified and embryos viability was evaluated throughout tetrazolium test. Data analysis was made based on the GLM procedure of the R program. Higher production of fruits and seeds was showed in controlled pollination when compared to open pollination. It can be concluded that controlled pollination after the anthesis of this species must be lead in two consecutive days to ensure a good seed production for mate.
\end{abstract}

Keywords: Mate; Phenology; Seeds.

\footnotetext{
${ }^{1}$ Recebido em 07.08.2013 aceito para publicação em 08.10.2014.

${ }^{2}$ Empresa Brasileira de Pesquisa Agropecuária, Centro Nacional de Pesquisa de Florestas, Guaraituba, Colombo, PR - Brasil. E-mail:<valderes.sousa@embrapa.br>e<ananda@cnpf.embrapa.br>.

${ }^{3}$ Instituto de Pesquisas Jardim Botânico Rio de Janeiro, Escola de Botânica Tropical, Mestrado em Botânica, Rio de Janeiro, RJ - Brasil. E-mail: <janspoladore@gmail.com>.
} 


\section{INTRODUÇÃO}

A erva-mate (Ilex paraguariensis A. St. Hil.) apresenta grande importância econômica no Brasil (FAOSTAT, 2013), especialmente na Região Sul, onde a produção nacional em 2011, segundo o IBGE, foi de 229.681 toneladas $(\mathrm{t})$, sendo $169.549 \mathrm{t}$ produzidas no Estado do Paraná, 36.117 t em Santa Catarina, 23.579 t no Rio Grande do Sul e 436 t no Mato Grosso do Sul, totalizando R \$ 118,00 milhões para o Produto Interno Bruto (PIB) nacional.

Embora a erva-mate tenha mercado consistente no Sul do Brasil com a produção e comercialização, sobretudo do chimarrão, seus plantios não são exclusivos do país. Além do Brasil, a Argentina e o Paraguai produzem a erva, que é nativa na Província de Missiones (Argentina) e na região entre os rios Paraná e Paraguai, no Paraguai (RESENDE et al., 2000).

No Brasil, a espécie ocorre naturalmente nos Estados do Centro-Oeste (Mato Grosso e Mato Grosso do Sul) e Sudeste (Minas Gerais e São Paulo) e Sul (Paraná, Santa Catarina e Rio Grande do Sul) (GROPPO, 2013).

As folhas e ramos da espécie são as partes coletadas no processo de extração e utilizadas na produção de chás e chimarrão, mas há interesse também na planta como um todo para usos diversos (GAUER; CAVALLIMOLINA, 2000; COELHO et al., 2002), o que tem gerado crescente interesse internacional pela espécie. Fato esse que tem permitido aumento nas exportações dos produtos industrializados e extrato da erva-mate destinado à indústria de cosméticos, incentivando, assim, o aumento de sua área de plantio.

A erva-mate é planta alógama dioica críptica (CARVALHO, 2003), não possibilitando a autopolinização. Dessa forma, a dioicia é um mecanismo determinante para a alogamia, pois favorece cruzamentos aleatórios por meio da polinização cruzada, que estimula a panmixia e permite a participação proporcional dos gametas no "pool" gênico, não reduzindo o tamanho efetivo populacional (SOUSA et al., 2003).

As flores da erva-mate são brancas e pequenas, dispostas em cacho fusiforme. O florescimento da planta ocorre de setembro a novembro no Paraná, de setembro a dezembro em Santa Catarina e de setembro a outubro no Rio Grande do Sul. Em árvores originadas de propagação vegetativa, os processos reprodutivos têm início dois anos após o plantio e em árvores originárias de plantio por sementes, cinco anos depois (CARVALHO, 1994; CORRÊA et al., 1999; CARVALHO, 2003).

Na erva-mate, a polinização é entomófila, e os grãos de pólen permanecem unidos devido à ação de uma substância oleosa denominada Pollenkitt, que também possibilita a adesão deles ao corpo dos insetos polinizadores (SANTOS; MARIATH, 2000). Quanto ao sistema reprodutivo da erva-mate, há a sugestão da presença de apomixia facultativa (DALL'AGNOL; SCHIFINO-WITTMANN, 2005).

Gorenstein et al. (2007), ao analisarem a evolução brasileira da cultura de erva-mate entre os anos de 1995-2005, concluíram que, apesar do aumento da área de cultivo, houve redução da produtividade, o que está diretamente relacionado à má qualidade das mudas, como esclarecem estudos de Sturion (1988) e Wendling et al. (2007). Portanto, melhorias do sistema de tecnologia de produção são necessárias para evitar a substituição da erva-mate por culturas mais produtivas. Para tanto, são imprescindíveis as atividades de pesquisas na área de produção de mudas de qualidade e o avanço dos programas de melhoramento genético visando à produção de materiais mais produtivos.

Entre as inúmeras estratégias adotadas para obtenção de material melhorado, a hibridação a partir da polinização controlada é a atividade que pode contribuir para esse processo, por possibilitar o cruzamento de materiais com características complementares e produtivos. Para isso, faz-se necessário o desenvolvimento de técnicas para viabilizar esse processo e garantir produtividade mais efetiva de sementes com qualidade, baseando-se no conhecimento prévio sobre fenologia e sistema reprodutivo da espécie (GUSSON et al., 2006). O conhecimento da fenologia reprodutiva é indispensável, pois as informações observadas nas fenofases, especificamente floração e frutificação, para este estudo, permitem definir o ciclo anual da espécie (ANDREIS et al., 2005), como o período de abertura das flores e intensidade de florescimento e o período ideal para a manipulação do pólen viável na população de escolha. O reconhecimento do período em que a receptividade do estigma é máxima é importante para o sucesso da polinização controlada com maior eficácia na produção de frutos e sementes. Para determinação desse período, podem ser utilizados testes histoquímicos diretos (STIEHL-ALVES; MARTINS, 2008), 
como o uso de peróxido de hidrogênio ou a medida indireta a partir da quantificação de frutos e sementes produzidos na polinização controlada (LAWINSCKY, 2010).

Diante desse contexto, este trabalho teve como objetivo definir a metodologia para a polinização controlada em matrizes de erva-mate que maximize a produção de sementes. Para tanto, foram utilizados diferentes tratamentos para inferência do período (dia ou combinação dos dias, após a antese) que propicia maior quantidade de frutos e sementes por frutos em relação à polinização livre.

\section{MATERIAL E MÉTODOS}

\subsection{Local de estudo}

O experimento de polinização controlada em ervamate foi realizado em três indivíduos femininos pertencentes a um teste clonal de 15 anos de idade, localizado nas dependências da Embrapa Florestas no Município de Colombo, no Estado do Paraná.

\subsection{Polinização}

Para isso, vários galhos de três árvores com botões próximos à antese foram isolados com tecido não tramado (TNT), tendo sido eliminadas as flores abertas para assegurar à produção o uso de pólens viáveis e não contaminados. O isolamento foi feito para assegurar a não contaminação por pólens estranhos e inviáveis de flores abertas anteriormente. Para o procedimento da polinização controlada, todos os botões verdes foram eliminados com uma tesoura, permanecendo, em média, 53 flores por tratamento (três árvores). Os seguintes tratamentos foram aplicados em três árvores femininas distintas (repetições): T1: polinização no primeiro dia após a antese; T2: polinização no segundo dia após a antese; T3: polinização no terceiro dia após a antese; T4: polinização no primeiro e segundo dias após a antese; T5: polinização no primeiro e terceiro dias após a antese; T6: polinização no segundo e terceiro dias após a antese; T7: polinização no primeiro, segundo e terceiro dias após a antese; T8: sem polinização, verificação de possível apomixia (formação de sementes sem fecundação); e T9: polinização livre (testemunha). Além disso, galhos referentes ao tratamento 8 foram isolados para observação de possível formação de frutos sem polinização (apomixia). O tratamento 9, polinização livre, foi usado para comparação com os tratamentos de polinização controlada, para inferência sobre a eficiência desse procedimento.

As polinizações controladas, conforme os tratamentos descritos anteriormente, foram realizadas com o mix de pólen coletado de flores masculinas abertas, ao acaso, no primeiro dia após a antese. Esse procedimento foi repetido nos dois dias subsequentes (segundo e terceiro dias). Os mesmos galhos isolados (TNT) foram mantidos para as polinizações do segundo e terceiro dias. Sacos com um visor afixado para evitar a contaminação dos botões polinizados foram usados para acompanhamento visual da polinização.

No estágio final de acompanhamento do crescimento dos frutos, para evitar a perda destes por queda e ataque de aves e insetos os sacos de TNT foram substituídos por sacos de filó.

\subsection{Coleta e processamento dos frutos}

O efeito da polinização foi avaliado inferindo-se os estágios de desenvolvimento do fruto semanalmente, de novembro de 2010 até o início de março de 2011. Os frutos foram coletados e suas sementes, extraídas usando o processo de maceração em peneira sob água corrente.

\subsection{Sementes}

As sementes coletadas, por tratamento, foram submetidas à secagem por $24 \mathrm{~h}$ à temperatura ambiente e, posteriormente, armazenadas em envelopes de papel sob refrigeração $\left(5^{\circ} \mathrm{C}\right)$. Em seguida, a viabilidade das sementes foi testada, empregando-se o teste de tetrazólio.

\subsection{Teste do tetrazólio}

As sementes foram mantidas em recipientes contendo água destilada por $24 \mathrm{~h}$ sob temperatura de $30{ }^{\circ} \mathrm{C}$, para facilitar a realização de cortes longitudinais. Tanto o endosperma quanto o embrião foram submetidos à solução de tetrazólio $1 \%$ por $24 \mathrm{~h}$, em germinador a $35^{\circ} \mathrm{C}$, no escuro. A viabilidade das sementes foi avaliada com o auxílio de lupa e por meio de parâmetros de cor (Tabela 1) adaptados de Catapan (1998).

\subsection{Parâmetros avaliados e análise estatística conduzida}

Os caracteres avaliados após a aplicação dos tratamentos foram: produção média de frutos e sementes (NF e NS), quantidade média de sementes por fruto (NSF), porcentagem de frutos e sementes formados

Revista Árvore, Viçosa-MG, v.39, n.2, p.315-323, 2015 
Tabela 1 - Padrões de cor para verificação da viabilidade de sementes de Ilex paraguariensis. Table 1 - Color standards for evaluation of seed viability in Ilex paraguariensis.

\begin{tabular}{cl}
\hline Padrão & \multicolumn{1}{c}{ Descrição das sementes } \\
\hline 1 & Endosperma colorido sem embrião visível \\
2 & Endosperma não colorido sem embrião visível \\
3 & Endosperma colorido com embrião colorido \\
4 & Endosperma colorido com embrião não colorido \\
5 & Endosperma não colorido com embrião colorido \\
6 & Endosperma não colorido com embrião não colorido \\
7 & Deterioradas \\
8 & Vazias \\
\hline
\end{tabular}

Padrões 3 e 5 definem sementes viáveis.

Standards 3 and 5 set viable seeds.

Fonte: Adaptado de CATAPAN, 1998.

Source: Adapted from CATAPAN, 1998.

por flores polinizadas (TPF e PSP) e viabilidade das sementes por fruto e flores polinizadas (NSVF e NSVP). Esses dados foram comparados à produção de frutos, sementes e viabilidade das sementes/embrião dos galhos de polinização livre (T9 - testemunha), para a inferência da eficiência da polinização controlada.

Procedeu-se, então, à análise de deviance através do delineamento estatístico de blocos completos ao acaso, com nove tratamentos e três repetições, considerando a distribuição normal (REML - Máxima Verossimilhança Restrita), para as variáveis número de frutos, taxa de pegamento de frutos e número de sementes; e a Poisson (LM - Máxima Verossimilhança), para porcentagem de sementes/flores polinizadas, número de sementes por fruto, número de sementes viáveis/ flores polinizadas e número de sementes viáveis por fruto. Para efeito de comparação de tratamentos, os nove graus de liberdade foram decompostos em contrastes ortogonais. Em seguida, foi aplicado o teste de Tukey. As análises estatísticas foram realizadas com base no procedimento GLM, do programa estatístico R.

\section{RESULTADOS}

De maneira geral, não houve sincronia na abertura das flores entre as árvores femininas e entre estas e as masculinas, nos dias de execução da polinização controlada.

Do total de flores polinizadas (53 flores por tratamento), verificou-se a formação de $48,25 \%$ de frutos. A porcentagem de pegamento de frutos variou de $22,22 \%$ (polinização no terceiro dia após a antese-T3) a 70,97\% (polinização no segundo e terceiro dias após a antese
- T6). A taxa média de pegamento dos frutos para a polinização livre (T9) também foi expressiva (58,33\%), em comparação com alguns tratamentos realizados, mas inferior ao T6, que atingiu sucesso de 70,97\%. A porcentagem para frutos não polinizados (formados possivelmente por apomixia (T8)) foi de apenas $16,67 \%$.

A análise de deviance (Tabela 2) apontou diferenças significativas entre tratamentos e blocos (árvores) para as características número de frutos (NF), taxa de pegamento dos frutos (TPF), número de sementes (NS), porcentagem de sementes/flores polinizadas (PSP) e número de sementes viáveis por fruto (NSVF). Para os demais caracteres analisados, não foram observadas diferenças significativas entre tratamentos. As diferenças detectadas entre tratamentos mostraram o efeito da metodologia de polinização controlada nas quantidades de frutos e sementes. Esse resultado será mais bem esclarecido com base nos contrastes ortogonais e no teste de comparação entre médias.

Com base no resultado do contraste ortogonal (Tabela 3), detectaram-se diferenças significativas para as características número de frutos (NF), taxa de pegamento de frutos por flores polinizadas por tratamento (TPF) e número de sementes (NS) entre a testemunha e os demais tratamentos e entre os tratamentos (1-7) versus o tratamento 8 (Tabela 3 ). Diferenças significativas também foram detectadas nos seguintes pares de contrastes T4-5 e T6 e T1-2 e T3, para a maioria dos caracteres relacionados à produção de frutos e sementes (Tabela 3). Quando se contrastou T1-3 vs. T4-6, foram observadas diferenças somente para três caracteres. Verificaram-se maiores diferenças entre os tratamentos em que a polinização foi realizada nos dois primeiros 
dias após a antese versus os dois últimos dias. Isso é confirmado com os resultados dos contrastes entre os tratamentos T1 e T2 e T4 vs. T5, em que não foi detectada diferença significativa para todos os caracteres.

Entre os tratamentos de polinização controlada realizados (T1 ao T7), a maior porcentagem na produção de frutos e sementes (NF e NS) resultou da polinização efetuada no segundo e terceiro dias após a antese (T6) (Tabela 4). Para as flores não polinizadas (T8), observou-se a mais baixa porcentagem de frutos e sementes. As flores de polinização livre (T9) geraram valores acima de $50 \%$ para ambas as características.

Em relação ao número de sementes por fruto, o tratamento 3 (polinização somente no terceiro dia após a antese) apresentou o menor valor médio $(3,20)$. A segunda menor média foi a da testemunha (polinização livre - T9), que apresentou a média de 3,96 sementes por fruto contra 4,02 do T6, o tratamento mais eficiente em relação a número de frutos e sementes, demonstrando a maior eficiência da polinização controlada.

Tabela 2 - Resultados da análise de deviance de diferentes tipos de polinização controlada em erva-mate.

Table 2 - Results of deviance analysis for different types of controlled pollination in mate.

\begin{tabular}{cccccccc}
\hline \multirow{2}{*}{ Efeitos } & \multicolumn{5}{c}{ Características } \\
\cline { 2 - 7 } & NF & TPF $(\%)$ & NS & PSP (\%) & NSF & NSVP & NSVF \\
\hline Blocos & $69,52^{*}$ & $261,95^{*}$ & $286,31^{*}$ & $11043,80^{*}$ & 1,60 & $5,20^{*}$ \\
Tratamentos & $42,99^{*}$ & $139,33^{*}$ & $175,18^{*}$ & $6983,80^{*}$ & 1,59 & 3,57 & $8,17 *$ \\
Resíduo & 26,53 & 122,62 & 111,13 & 4060,10 & 0,19 & 1,63 & 3,86 \\
Modelo & 90,21 & 289,57 & 361,90 & 12536,50 & 1,61 & 7,20 \\
\hline
\end{tabular}

$\mathrm{NF}=$ Número de frutos; TFP $=$ Taxa de pegamento de frutos por flores polinizadas por tratamento; NS = número de sementes; PSP = Porcentagem de sementes por flores polinizadas por tratamento; NSF = Número de sementes por fruto por tratamento; NSVP = Número de sementes viáveis por flores polinizadas por tratamento; e NSVF $=$ Número de sementes viáveis por fruto por tratamento. $*$ LRT $=$ Teste de verossimilhança, Qui-quadrado tabelado para o nível de significância de $1 \%(6,63)$ e de $5 \%(3,84)$.

Tabela 3 - Resultados da análise de composição do efeito de tratamentos em contrastes ortogonais, considerando-se os nove tratamentos de polinização em erva-mate

Table 3 - Results of composition analysis of treatments effect on orthogonal contrasts considering nine pollination treatments in mate

\begin{tabular}{|c|c|c|c|c|c|c|c|}
\hline \multirow{2}{*}{ Efeitos } & \multicolumn{7}{|c|}{ Características } \\
\hline & $\mathrm{NF}^{1}$ & TPF $(\%)^{1}$ & $\mathrm{NS}^{1}$ & $\operatorname{PSP}(\%)^{2}$ & $\mathrm{NSF}^{2}$ & $\mathrm{NSVP}^{2}$ & $\mathrm{NSVF}^{2}$ \\
\hline \multirow[t]{2}{*}{ T1-8 vs T9 } & $-0,397^{3}$ & $-0,293$ & $-0,389$ & $-10,791$ & $-2,101$ & - & - \\
\hline & $(0,036)$ & $(0,000)$ & $(0,000)$ & $(0,365)$ & $(0,796)$ & - & - \\
\hline \multirow[t]{2}{*}{$\mathrm{T} 1-7$ vs $\mathrm{T} 8$} & 0,973 & 0,867 & 0,921 & 28,512 & $-1,596$ & 0,319 & 1,004 \\
\hline & $(0,008)$ & $(0,000)$ & $(0,000)$ & $(0,063)$ & $(0,125)$ & $(0,263)$ & $(0,037)$ \\
\hline \multirow[t]{2}{*}{ T1-6 vs T7 } & 0,391 & 0,353 & 0,302 & 14,859 & $-3,667$ & 0,574 & 0,354 \\
\hline & $(0,111)$ & $(0,000)$ & $(0,011)$ & $(0,228)$ & $(0,000)$ & $(0,122)$ & $(0,511)$ \\
\hline \multirow[t]{2}{*}{$\mathrm{T} 1-3$ vs T4-6 } & $-0,142$ & $-0,201$ & $-0,199$ & $-12,647$ & $-2,672$ & $-0,368$ & 0,348 \\
\hline & $(0,423)$ & $(0,010)$ & $(0,028)$ & $(0,233)$ & $(0,002)$ & $(0,208)$ & $(0,439)$ \\
\hline \multirow[t]{2}{*}{$\mathrm{T} 1-2$ vs T3 } & 0,590 & 0,803 & 0,752 & 42,348 & 8,108 & 1,177 & $-0,664$ \\
\hline & $(0,064)$ & $(0,000)$ & $(0,000)$ & $(0,017)$ & $(0,000)$ & $(0,040)$ & $(0,402)$ \\
\hline \multirow[t]{2}{*}{$\mathrm{T} 4-5$ vs T6 } & $-0,907$ & $-0,607$ & $-0,924$ & $-38,897$ & $-4,267$ & $-0,363$ & 0,420 \\
\hline & $(0,000)$ & $(0,000)$ & $(0,000)$ & $(0,028)$ & $(0,689)$ & $(0,340)$ & $(0,468)$ \\
\hline \multirow[t]{2}{*}{$\mathrm{T} 1$ vs $\mathrm{T} 2$} & $-0,188$ & $-0,205$ & $-0,188$ & $-12,997$ & 1,068 & 0,447 & 1,220 \\
\hline & $(0,454)$ & $(0,049)$ & $(0,134)$ & $(0,404)$ & $(1,000)$ & $(0,231)$ & $(0,048)$ \\
\hline \multirow[t]{2}{*}{$\mathrm{T} 4 v s \mathrm{~T} 5$} & $-0,026$ & 0,078 & $-0,021$ & 3,286 & 3,466 & 0,723 & 1,240 \\
\hline & $(0,935)$ & $(0,572)$ & $(0,894)$ & $(0,851)$ & $(0,774)$ & $(0,103)$ & $(0,073)$ \\
\hline
\end{tabular}

$\mathrm{NF}=$ Número de frutos; TFP = Taxa de pegamento de frutos por flores polinizadas por tratamento; NS = número de sementes; PSP = Porcentagem de sementes por flores polinizadas por tratamento; NSF $=$ Número de sementes por fruto por tratamento; NSVP $=$ Número de sementes viáveis por flores polinizadas por tratamento; NSVF = Número de sementes viáveis por fruto por tratamento. ${ }^{1}$ Distribuição normal, ${ }^{2}$ Distribuição de Poisson e ${ }^{3}$ Estimativas das diferenças de médias; ( ) Probabilidade de significância (p-valor). 
A viabilidade das sementes, definida a partir do teste do tetrazólio (Figura 1), evidenciou que 99,41\% das sementes avaliadas eram viáveis e somente $0,59 \%$, vazias. Duas sementes apresentavam inseto no seu interior, mas com endospermas perfeitamente viáveis, razão por que não foram consideradas sementes cheias.

\section{DISCUSSÃO}

Houve assincronia dos eventos reprodutivos (diferenciação da gema floral, florescimento e frutificação) tanto para flores femininas quanto masculinas, durante toda a fenofase reprodutiva. A sincronia foi registrada apenas para um indivíduo. $\mathrm{O}$ assincronismo pode limitar a troca gênica, favorecendo a autopolinização e cruzamento entre indivíduos aparentados (FERES et al., 2012), o que induz o isolamento reprodutivo e diminui o tamanho efetivo populacional, com a perda de alelos (GONÇALVES; PIÑARODRIGUES, 2007), fato que torna a polinização controlada interessante, do ponto de vista genético. A falta de sincronia entre receptividade das flores masculinas e femininas dificulta a polinização de grande quantidade de flores e torna o processo

Tabela 4 - Valores médios de número de frutos por tratamento (NF), taxa de pegamento dos frutos (TPF), número de sementes por tratamento (NS), porcentagem de sementes/flores polinizadas por tratamento (PSP), número de sementes por fruto por tratamento (NSF), número de sementes viáveis/flores polinizadas por tratamento (NSVP), número de sementes viáveis por fruto por tratamento (NSVF) para erva-mate.

Table 4 - Mean values for number of fruits per treatment (NF), fruits fixation rate (FFR), number of seeds per treatment (NS), percentage of seeds/pollinated flowers per treatment (PSP), number of seeds per fruit per treatment (NSF), number of viable seeds/pollinated flowers per treatment (NVSP), number of viable seeds per fruit per treatment (NVSF) to mate.

\begin{tabular}{cccccccc}
\hline \multirow{2}{*}{ Trat. } & \multicolumn{7}{c}{ Características } \\
\cline { 2 - 8 } & NF & TPF $(\%)$ & NS & PSP (\%) & NSF & NSVP & NSVF \\
\hline 1 & $9,67 \mathrm{~A}$ & $55,46 \mathrm{C}$ & $38,67 \mathrm{~B}$ & $55,46 \mathrm{~A}$ & $4,00 \mathrm{~A}$ & $1,50 \mathrm{~A}$ & $2,76 \mathrm{~A}$ \\
2 & $11,67 \mathrm{~A}$ & $68,45 \mathrm{~A}$ & $46,67 \mathrm{~B}$ & $68,45 \mathrm{~A}$ & $4,00 \mathrm{~A}$ & $1,05 \mathrm{~A}$ & $1,54 \mathrm{~A}$ \\
3 & $6,00 \mathrm{~B}$ & $30,55 \mathrm{D}$ & $20,25 \mathrm{~B}$ & $25,47 \mathrm{~B}$ & $3,20 \mathrm{~B}$ & $0,33 \mathrm{~A}$ & $3,00 \mathrm{~A}$ \\
4 & $7,33 \mathrm{~B}$ & $49,17 \mathrm{D}$ & $29,33 \mathrm{~B}$ & $49,17 \mathrm{~A}$ & $4,00 \mathrm{~A}$ & $1,49 \mathrm{~A}$ & $2,79 \mathrm{~A}$ \\
5 & $9,00 \mathrm{~B}$ & $43,57 \mathrm{D}$ & $35,50 \mathrm{~B}$ & $42,97 \mathrm{~A}$ & $3,96 \mathrm{~A}$ & $0,65 \mathrm{~A}$ & $1,45 \mathrm{~A}$ \\
6 & $22,00 \mathrm{~A}$ & $83,07 \mathrm{~A}$ & $88,50 \mathrm{~A}$ & $83,51 \mathrm{~A}$ & $4,02 \mathrm{~A}$ & $1,37 \mathrm{~A}$ & $1,65 \mathrm{~A}$ \\
7 & $6,33 \mathrm{C}$ & $36,67 \mathrm{D}$ & $27,00 \mathrm{~B}$ & $39,31 \mathrm{~A}$ & $4,23 \mathrm{~A}$ & $0,37 \mathrm{~A}$ & $1,75 \mathrm{~A}$ \\
8 & $4,00 \mathrm{D}$ & $20,00 \mathrm{D}$ & $16,50 \mathrm{~B}$ & $20,62 \mathrm{~B}$ & $4,07 \mathrm{~A}$ & - & - \\
9 & $11,67 \mathrm{~A}$ & $59,82 \mathrm{~B}$ & $46,00 \mathrm{~B}$ & $59,27 \mathrm{~A}$ & $3,96 \mathrm{~A}$ & $0,66 \mathrm{~A}$ & $1,13 \mathrm{~A}$ \\
\hline
\end{tabular}

Médias seguidas pela mesma letra não diferem estatisticamente, com base no teste de Tukey (contrastes), considerando-se a distribuição normal e de Poisson a $1 \%$ de significância.

Fonte: Janaína Spoladore.

Source: Janaína Spoladore.
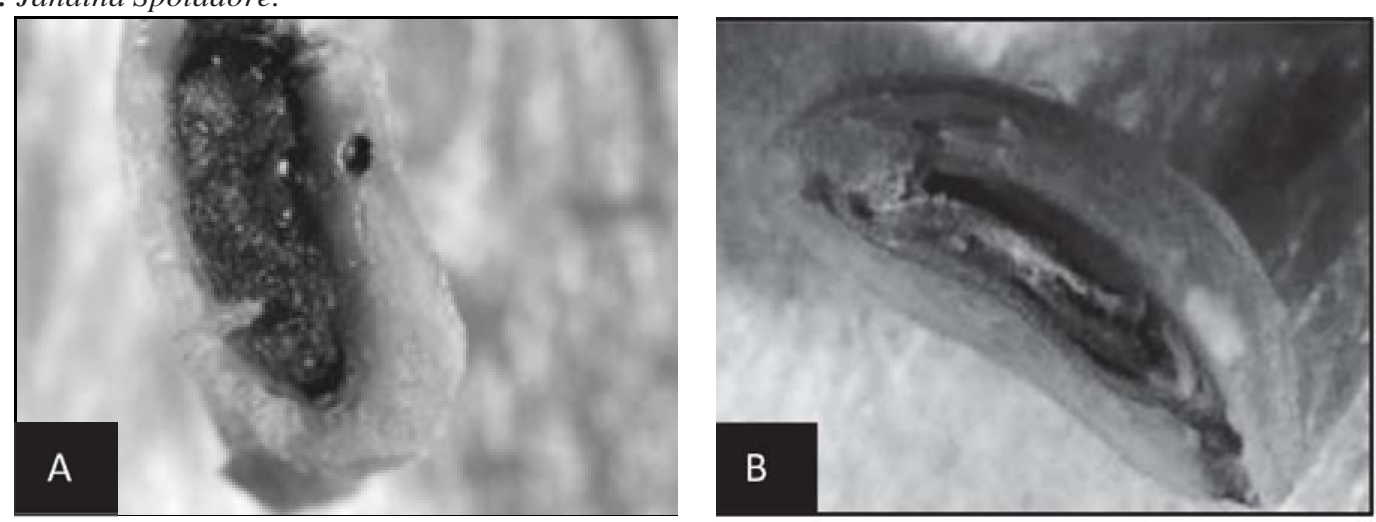

Figura 1 - Semente cheia (A); semente vazia (B).

Picture 1 - Full seed (A); empty seed (B).

Revista Árvore, Viçosa-MG, v.39, n.2, p.315-323, 2015 
oneroso. Após a antese, as estruturas reprodutivas permaneceram intactas, só modificando a coloração no final do quarto dia, quando algumas pétalas das flores femininas começaram a apresentar sinais de escurecimento, assim como observado por Stiehl-Alves e Martins (2008) e por Silva et al. (2010), em diferentes espécies, indicando, através de análise indireta, possivelmente perda na receptividade do estigma.

Os resultados da polinização livre (58,33\%) devem estar relacionados à eficiência dos polinizadores naturais observados na área experimental, como dípteros (moscas) e himenópteros (abelhas), segundo Ayub e Mariath (1996 apud CARVALHO, 2003). No entanto, a porcentagem de pegamento de frutos de $70,97 \%$, cuja polinização foi realizada em dois dias consecutivos, demonstra o sucesso da polinização controlada. Na mesma área experimental, Garcia et al. (2010) verificaram $61,43 \%, 66,16 \%$ e $52,43 \%$ de pegamento dos frutos de erva-mate quando a polinização foi realizada somente no primeiro dia, em dois dias e em três dias consecutivos após a antese, respectivamente. Tais resultados, apesar de apresentarem valores diferentes dos obtidos neste trabalho, confirmam que a polinização de erva-mate efetuada em dois dias consecutivos contribui para a maior produção de frutos. Essa maior produtividade também pode estar relacionada com a maior receptividade do estigma indiretamente analisada por meio da maior produção de frutos e sementes (LAWINSCKY, 2010) e também por ocorrer menos manipulação floral quando comparada com a polinização por três dias consecutivos, pois se deve considerar que a manipulação excessiva das estruturas florais geralmente provoca perda das flores e redução de produtividade.

O menor valor médio $(3,20)$ de sementes por fruto apresentado no Tratamento 3 (polinização somente no terceiro dia após a antese) sugere, possivelmente, a redução da receptividade do estigma, uma vez que o pólen utilizado foi sempre fresco.

No Tratamento 8 (possível apomixia, sem polinização), não foi realizado teste de tetrazólio, por se tratar de um teste destrutivo e do fato de a germinação e genotipagem das plantas serem de interesse para a verificação de possível apomixia ou contaminação, embora esta última possibilidade seja muito remota, uma vez que os sacos usados para isolamento das flores foram confeccionados com camada dupla, e todo o cuidado foi tomado na manipulação das flores. Vale ressaltar que, embora Sousa et al. (2003) e Wendt (2005) sugiram a formação de frutos apomíticos (apomixia facultativa) em erva-mate, estudos sobre o assunto devem ser ainda concluídos.

A polinização controlada foi mais eficiente, tanto para a maior formação de frutos quanto de sementes de erva-mate, pois os resultados foram superiores nos tratamentos em que se realizou a polinização controlada. Portanto, a polinização controlada pode ser adotada em maior escala se houver necessidade de aumentar a produção de sementes de genótipos selecionados e de ser adotada com sucesso para a produção de híbridos e obtenção de descendentes com maior vigor na característica de interesse.

Finalmente, verificou-se que o período mais indicado para a polinização controlada, com pólen fresco, em erva-mate é de dois e três dias consecutivos após a antese da flor, visto que esse procedimento contribuiu para a maior porcentagem de formação de frutos e sementes viáveis.

\section{CONCLUSÕES}

A polinização controlada, na forma realizada neste trabalho, é eficiente para a produção de sementes de erva-mate quando confrontada com a polinização livre.

A polinização controlada realizada dois dias consecutivos (dias 2 e 3 ) após a antese é indicada por produzir maior número de frutos e sementes viáveis, sendo, portanto, essa a combinação de dias mais adequada para maior eficiência da polinização.

\section{AGRADECIMENTOS}

Aos técnicos da Embrapa Florestas, pelo auxílio na execução do experimento e pela análise das amostras de sementes.

\section{REFERÊNCIAS}

ANDREIS, C.; LONGUI, S. J.; BRUN, E. J.; WOJCIECHOWSKI, J. C.; MACHADO, A. A.; VACCARO, S.; CASSAL, C. Z. Estudo fenológico em três fases sucessionais de uma floresta estacional decidual no município de Santa Tereza, RS, Brasil. Revista Árvore, v.29, n.1, p.55-63, 2005.

CARVALHO, P. E. R. Espécies Florestais Brasileiras: Recomendações silviculturais, potencialidades e uso da madeira. Colombo: Empresa Brasileira de Pesquisa Agropecuária,

Revista Árvore, Viçosa-MG, v.39, n.2, p.315-323, 2015 
Centro Nacional de Pesquisa de Florestas/ Embrapa-CNPF; Brasília: Embrapa-SPI, 1994. p.280-287

CARvalho, P. E. R. Espécies Arbóreas Brasileiras. Brasília: Embrapa Informação Tecnológica; Colombo: Embrapa Florestas, 2003. v.1.p.455-466.

CATAPAN, M. I. S. Influência da

Temperatura, Substrato e Luz na Germinação de Sementes de Ilex paraguariensis St. Hil. 1998. 97f. Dissertação (Mestrado em Ciências Florestais) - Setor de Ciências Agrárias, Universidade Federal do Paraná, Curitiba, 1998.

COELHO, G. C.; MARIATH, J.E.A.; SCHENKEL, E.P. Population diversity on leaf morphology of Maté (Ilex paraguariensis A.St.-Hil., Aquifoliaceae). Brazilian Arquives of Biology and Technology, An International Journal, v.45, n.1, p. 47-51, 2002.

CORRÊA, S.; KIST, B. B.; QUINTANA, A. Anuário Brasileiro da Erva-Mate 1999. Santa Cruz do Sul: Gazeta Grupo de Comunicações, 1999.

DALL'AGNOL, M.; SCHIFINO-WITTMANN, M. T. Apomixia, genética e melhoramento de plantas. Revista Brasileira Agrociência, v.11, n.2, p.127-133, 2005.

\section{FAOSTAT. FOOD AND AGRICULTURE} ORGANIZATION OF THE UNITED NATIONS. Disponível em: <HTTP: http://faostat.fao.org/ DesktopDefault.aspx?PageID=339\&lang=en $>$ Acesso em: 04 nov. 2013.

FERES, J. M. et al. Mating system parameters at hierarchical levels of fruits, individuals and populations in the Brazilian insect-pollinated tropical tree, Tabebuia roseo-alba (Bignoniaceae). Conservation Genetcs, v.13, p.393-405, 2012.

GARCIA, D. K.; SOUSA, V. A.; STURION, J. A. Desenvolvimento de técnicas para polinização controlada em erva-mate (Ilex paraguariensis St. Hil). In: EVENTO DE INICIAÇÃO CIENTÍfICA, 9., 2010, Colombo. Evento.... Colombo: Embrapa Florestas, 2010.
GAUER, L.; CAVALLI-MOLINA, S. Genetic variation in natural populations of Maté (Ilex paraguariensis. A.St.-Hil., Aquifoliaceae) using RAPD markers.

Heredity, v.84, p.647-656, 2000.

GONÇALVES, M. P. M.; PIÑA-RODRIGUES, F. C. M. Sistema de Reprodução de Lophanthera lactescens Juss (Malpighiaceae) em Área de Introdução.

Revista Científica Eletrônica de Engenharia Florestal, v.6, n.10, ago., 2007. Disponível em: <HTTP: www.revista.inf.br/ florestal10/pages/artigos/ARTIGO_02.pdf $>$ Acesso em: 5 mar. 2011.

GORENSTEIN, M. R.; BARBOSA, R. Z.; RIBEIRO, E. R.; BUENO, J. L.; FERNANDES, J. M. O.; PEREIRA, L. H. P. Evolução da cultura de erva-mate no Brasil durante o período de 1995-2005. Revista Científica Eletrônica de Agronomia, v.6, n.11, jun., 2007. Disponível em: $<$ HTTP: www.revista.inf.br/agro11/artigos/anovi-edic11art05.pdf $>$ Acesso em: 7 ago. 2010.

GROPPO, M. Aquifoliaceae in Lista de Espécies da Flora do Brasil. Rio de Janeiro: Jardim Botânico do Rio de Janeiro, 2013. Disponível em: <HTTP: www.floradobrasil.jbrj.gov.br/jabot/ floradobrasil /FB4904> Acesso em: 11 set. 2010.

GUSSON, E.; SEBBENN, A. M.; KAGEYAMA, P. Y. Sistema de reprodução em populações de Eschweilera ovata (Cambess.) Miers. Revista Árvore, v.30, n.4, p.491-502, 2006.

INSTITUTO BRASILEIRO DE GEOGRAFIA E ESTATISTICA - IBGE. Produção da Extração Vegetal e da Silvicultura - 2011.

Disponível em: <HTTP: ftp://ftp.ibge.gov.br/ Producao Agricola/

Producao_da_Extracao_Vegetal_e_da_Silvicultura_[anual]/ 2011/pevs2011.pdf> Acesso em: 04 nov. 2013.

\section{LAWINSCKY, P. R. Caracterização} morfológica, reprodutiva e fenológica de Passiflora alata Curtis e Passiflora cincinnata Mast. 2010. 146f. Dissertação (Mestrado em Produção Vegetal) - Setor de Melhoramento Genético Vegetal, Universidade Estadual de Santa Cruz, Bahia, 2010.

RESENDE, M. D. V; STURION, J. A.; CARVALHO, A. P.; SIMEÃO, R. M.; FERNANDES, J. S. C. 
Programa de Melhoramento da ErvaMate coordenado pela Embrapa:

resultados da avaliação genética de populações, progênies, indivíduos e clones. Colombo: Embrapa Florestas, 2000. Disponível em: $<$ HTTP:

www.cnpf.embrapa.br/publica/circtec/edicoes/circtec43.pdf $>$ Acesso em: 15 jul. 2010.

SANTOS, R. P.; MARIATH, J. E. A. Embriologia de Ilex paraguariensis A. St. Hil.: Estudo da antera e grão de pólen e sua aplicação no melhoramento. In: WINGE, H. Anais do II

Congresso Sul-Americano da ErvaMate e III Reunião Técnica da ErvaMate. Porto Alegre: Edição dos Organizadores, 2000. p.140-142.

SILVA, C. A. et al. Variação na arquitetura floral e sucesso reprodutivo de duas espécies de Helicteres (Malvaceae), na região sudoeste de Mato Grosso. Acta Botanica Brasilica, v.24, n.2, abr./jun., 2010.

SOUSA, V. A.; DAROS, T. L.; STURION, J. A. Fenologia reprodutiva de Erva-Mate (Ilex paraguariensis St. Hil.). In: CONGRESSO FLORESTAL ESTADUAL DO RIO GRANDE DO SUL, 9., 2003, Nova Prata. Anais...Nova Prata: Prefeitura Municipal, 2003.

STIEHL-ALVES, E. M.; MARTINS, M. P. Biologia reprodutiva de Acacia mearnsii de Wild.: receptividade de estigmas. Revista Árvore, v.32, n.4, p.609-616, 2008.

Sturion, J. A. Produção de mudas e implantação de povoamentos com erva-mate. Curitiba: Embrapa CNPF, 1988. (Circular Técnica, 17).

WENDLING, I.; GUASTALA, D.; DEDECEK, R. Características físicas e químicas de substratos para produção de mudas de Ilex paraguariensis St. Hil. Revista Árvore, v.31, n.2, p.209-220, 2007.

WendT, S. N. Genética de Populações em Ilex paraguariensis St. Hil. 2005. 165f. Tese (Doutorado em Agroindústria) - Setor de Tecnologia, Universidade Federal do Paraná, Curitiba, 2005. 